\title{
A Comparative Study on Viewers' Perceptions of the Portrait of the MH370 Incident by the Social Media in Malaysia and China
}

Authors: Changsong, Wang ; Yiming, Chen ; Ahmad, Jamilah ; Jinsheng, Zhang ;

Source: Advanced Science Letters, Volume 23, Number 4, April 2017, pp. 3092-3096(5)

Publisher: American Scientific Publishers

DOI: https://doi.org/10.1166/asl.2017.7663

The $\mathrm{MH} 370$ incident demonstrated an unprecedented international humanitarian response from the technology sector. This study attempted to have a deep insight about online users' perceptions towards the portrait of this incident by the social media in Malaysia and China. Social networking sites such as Facebook (in Malaysia), Weibo (in China) and Wechat (in China), become the public opinion field that illustrates sorts of openness and negotiation in Malaysia and China. This study argued the technical and social knowledge to work with social media represents a steep learning curve for crisis managers who are used to working with traditional new media, as there is a significant relationship between empowerment of social media and effectiveness of crisis communication. The result of survey indicated different level of engagement with the content posted on social media in these two countries. This study proposes social media strategies that will be an integral part of any organization's plan to respond to an accident or major incident.

Keywords: China; Crisis Communication; MH370; Malaysia; Social Media 